Atmos. Chem. Phys., 3, 999-1005, 2003

www.atmos-chem-phys.org/acp/3/999/

\title{
The detection of solar proton produced ${ }^{14} \mathrm{CO}$
}

\author{
P. Jöckel ${ }^{1}$, C. A. M. Brenninkmeijer ${ }^{1}$, M. G. Lawrence ${ }^{1}$, and P. Siegmund ${ }^{2}$ \\ ${ }^{1}$ Department of Air Chemistry, Max-Planck-Institute for Chemistry, Mainz, Germany \\ ${ }^{2}$ Atmospheric Composition Division, Royal Netherlands Meteorological Institute (KNMI), De Bilt, The Netherlands
}

Received: 12 February 2003 - Published in Atmos. Chem. Phys. Discuss.: 27 March 2003

Revised: 12 June 2003 - Accepted: 11 July 2003 - Published: 14 July 2003

\begin{abstract}
Major solar eruptions (coronal mass ejections) are accompanied by massive ejections of protons. When these charged particles head for the Earth through the interplanetary magnetic field with high flux and energy, a solar proton event (SPE) is recorded. Strong SPEs, in which energetic protons penetrate the atmosphere in large numbers are rare, but do have chemical effects (Crutzen, 1975; Jackman et al., 1990, 2001). They also have nucleonic effects by which they can almost instantaneously increase the atmospheric production of radio-nuclides, including ${ }^{14} \mathrm{C}$ (radiocarbon), but this has never been demonstrated. We show, using satellite observations and modeling, that the 2nd most intensive set of SPEs on record, that of August-December 1989, must have caused detectable increases in atmospheric ${ }^{14} \mathrm{CO}$. This is confirmed by a sequence of peaks in the Baring Head (NZ) time series of ${ }^{14} \mathrm{CO}$ observations (Brenninkmeijer, 1993), probably providing a unique indication of production of ${ }^{14} \mathrm{C}$ by solar protons, thus demonstrating the use of $\mathrm{SPE}{ }^{14} \mathrm{CO}$ as an atmospheric tracer.
\end{abstract}

\section{Introduction}

The global annual, solar cycle averaged atmospheric production of $\approx 7 \mathrm{~kg}$ of ${ }^{14} \mathrm{C}$ atoms via ${ }^{14} \mathrm{~N}(\mathrm{n}, \mathrm{p}){ }^{14} \mathrm{C}$ by cosmic radiation (mainly from high energy protons) forms the basis for the widely applied radiocarbon dating (Libby, 1952). ${ }^{14} \mathrm{C}$ enters the biosphere as ${ }^{14} \mathrm{CO}_{2}$ through its assimilation by photosynthetic plants, and when for any living organism the exchange of ${ }^{14} \mathrm{C}$ with the atmosphere ceases, the radiocarbon decay clock starts to tick. It is well known that ${ }^{14} \mathrm{C}$ production has changed in the past, and that it varies with solar activity with a period of about 11 years. Yet, it has been shown that a $25 \%$ modulation (peak to peak) of the produc-

Correspondence to: P. Jöckel

(joeckel@mpch-mainz.mpg.de) tion of ${ }^{14} \mathrm{C}$ due to the 11 year solar cycle, leaves only a very weak signal in atmospheric ${ }^{14} \mathrm{CO}_{2}$ and in tree rings (Stuiver and Braziunas, 1993). The sudden increases associated with solar proton events can therefore certainly not be detected in ${ }^{14} \mathrm{CO}_{2}$ or in tree rings, because the reservoir of ${ }^{14} \mathrm{CO}_{2}$ is large. However, before ${ }^{14} \mathrm{C}$ enters the oceans and biosphere as ${ }^{14} \mathrm{CO}_{2}$, it resides in the atmosphere in the incompletely oxidized form of ${ }^{14} \mathrm{CO}$. Thus although a ${ }^{14} \mathrm{C}$ atom instantaneously oxidizes to ${ }^{14} \mathrm{CO}$ (Pandow et al., 1960; MacKay et al., 1963) the second chemical conversion,

${ }^{14} \mathrm{CO}+\mathrm{OH} \rightarrow{ }^{14} \mathrm{CO}_{2}+\mathrm{H}$

takes on the average some months. This rapid but not immediate turnover leads to a small but measurable ${ }^{14} \mathrm{CO}$ inventory; there are only 5 to $25{ }^{14} \mathrm{CO}$ molecules in $1 \mathrm{~cm}^{3}$ of tropospheric air near the surface, compared to $\approx 10^{4}{ }^{14} \mathrm{CO}_{2}$ molecules. This then allows the actual detection of ${ }^{14} \mathrm{C}$ production by SPEs, provided that observations of this ultra-low level tracer ${ }^{14} \mathrm{CO}$ do exist.

Observations of ${ }^{14} \mathrm{CO}$ have been made because it is the only natural atmospheric tracer available that can help to better quantify a fundamental property of the troposphere, namely its $\mathrm{OH}$ (hydroxyl) based oxidative activity or its selfcleansing capacity. With $\mathrm{OH}$ radicals constituting the main sink reaction of ${ }^{14} \mathrm{CO}$, and knowing its production rate, and measuring its levels in the atmosphere, $\mathrm{OH}$ abundance can be inferred according to equation (1) above (Volz et al., 1981; Brenninkmeijer et al., 1992; Mak and Southon, 1998; Jöckel et al., 1999, 2000, 2002; Jöckel and Brenninkmeijer, 2002). It is, however, in view of the rarity of SPEs, a coincidence that the second most powerful set of SPEs ever recorded, occurred just a few months after the first systematic observations of ${ }^{14} \mathrm{CO}$ had started on the planet. In the following we first calculate using satellite data, the production of ${ }^{14} \mathrm{C}$ during the fall 1989 SPEs. Next we calculate using a state of the art atmospheric chemistry transport model the expected

(C) European Geosciences Union 2003 


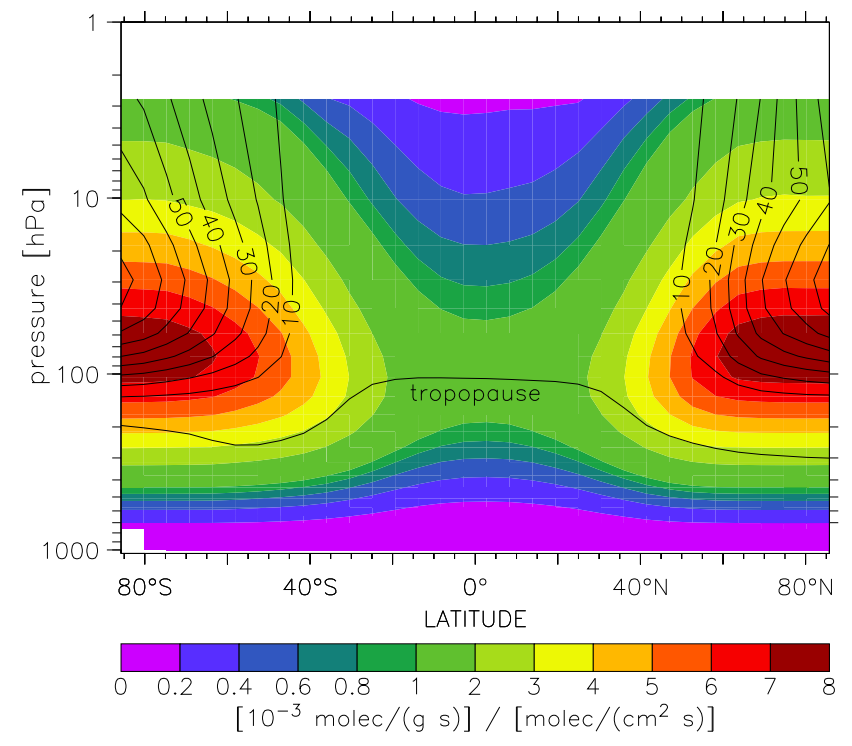

Fig. 1. Annual zonal mean galactic cosmic ray induced ${ }^{14} \mathrm{CO}$ production rate (GCR, shaded) and annual zonal mean solar proton event induced ${ }^{14} \mathrm{CO}$ production rate (SPE, contour lines). The unit is $10^{-3}$ molec g $\mathrm{g}^{-1} \mathrm{~s}^{-1}$ normalized to a global average production rate of 1 molec $\mathrm{cm}^{-2} \mathrm{~s}^{-1}$. The yield of ${ }^{14} \mathrm{CO}$ from ${ }^{14} \mathrm{C}$ oxidation is assumed to be $95 \%$. The plotted zonal average tropopause level between August and November is calculated from the NCEP reanalysis data for 1993 according to the WMO definition.

temporal changes in ${ }^{14} \mathrm{CO}$. Finally we analyze the Baring Head (NZ) ${ }^{14} \mathrm{CO}$ record for signs of these SPEs.

\section{Model simulations of SPE produced atmospheric ${ }^{14} \mathrm{CO}$}

About $50 \%$ of ${ }^{14} \mathrm{C}$ production by cosmic rays takes place in the stratosphere, whereas for solar protons, which have lower energies, the ${ }^{14} \mathrm{C}$ production maximum is shifted higher into the stratosphere (Fig. 1).

The energy spectrum of the 3 main 1989 SPEs (Fig. 2 gives the pulse shape) was measured by instruments of GOES-7 (Geostationary Operational Environmental Satellite). For solar protons the rigidity spectrum (momentum over charge) follows an exponential function with a characteristic rigidity $P_{0}$ from 50 to $325 \mathrm{MV}$ (Freier and Webber, 1963; Lingenfelter and Ramaty, 1970) and the total ${ }^{14} \mathrm{C}$ production (Table 1) is determined by $P_{0}$ and the flux $I$ (Sauer et al., 1990; Shea and Smart, 1992; Feynman et al., 1993).

Because geomagnetic shielding might be weakened during geomagnetic storms occurring coeval to the SPEs, ${ }^{14} \mathrm{C}$ production can be enhanced (Lingenfelter and Ramaty, 1970). Therefore Table 1 also includes estimates for an assumed $80 \%$ reduction in the cut-off rigidity (the minimum rigidity a proton needs to reach a particular point in the atmosphere). These estimates are considered as upper limits. Given both

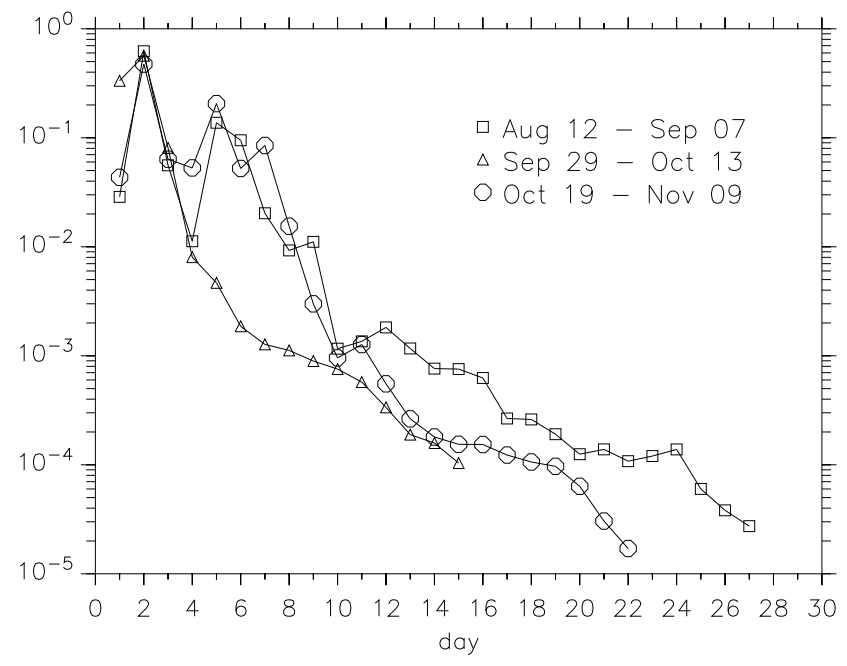

Fig. 2. Pulse shape of ${ }^{14} \mathrm{CO}$ production for the 3 major SPEs in 1989, based on GOES-7 solar proton flux measurements. The vertical axis measures the fraction of the total ${ }^{14} \mathrm{CO}$ production during the indicated time interval of the respective event.

background GCR (Lingenfelter, 1963) and the SPE produced ${ }^{14} \mathrm{C}$, a 3-dimensional atmospheric transport and chemistry model (see Appendix) is used to calculate the resulting ${ }^{14} \mathrm{CO}$ distribution (it is assumed that $95 \%$ of ${ }^{14} \mathrm{C}$ is instantaneously converted to ${ }^{14} \mathrm{CO}$, Pandow et al., 1960; MacKay et al., 1963). Essential is the spatial and temporal pattern of the production of ${ }^{14} \mathrm{CO}$, its transport in the atmosphere and its concurrent removal by $\mathrm{OH}$. The zonally averaged enhancement ratio of ${ }^{14} \mathrm{CO}$, given as the ratio $(\mathrm{SPE}+\mathrm{GCR}) / \mathrm{GCR}$, simulated for the lowest model layer (Fig. 3, left) shows that atmospheric ${ }^{14} \mathrm{CO}$ temporarily increases up to $22 \%$ several months after the SPEs.

A distinct asymmetry between the two hemispheres is predicted by the model. The simulated downward transport of ${ }^{14} \mathrm{CO}$ at this time of the year is almost as twice as effective in the northern hemisphere $(\mathrm{NH})$ compared to the southern hemisphere $(\mathrm{SH})$. Repeating the model simulation assuming an $80 \%$ reduced cut-off rigidity, the resulting signal shape of excess ${ }^{14} \mathrm{CO}$ is similar, however with a maximum increase of $55 \%$. The time lag between the largest SPE (No. 3 in Table 1) and maximum excess ${ }^{14} \mathrm{CO}$ is dependent on the location as shown in Fig. 3 (right). The model does not resolve the individual events (the 2 main events are only 3 weeks apart). One of the biggest challenges for contemporary chemistry transport models (CTMs) and general circulation models (GCMs) is still the realistic simulation of strength and phase of the stratosphere to troposphere exchange (STE). In order to resolve the three peaks, a much higher vertical resolution would be needed at least, and most probably also much improved advection algorithms. 
Table 1. Characteristic rigidity $P_{0}$, flux $I_{>30 \mathrm{MeV}}$ of protons with energy greater than $30 \mathrm{MeV}$, and estimated total ${ }^{14} \mathrm{CO}$ production for normal cut-off rigidity $\left(Q_{100 \%}\right)$ and an $80 \%$ reduced cut-off rigidity $\left(Q_{20 \%}\right)$ of the 3 major SPEs in 1989 . For comparison, the amount of ${ }^{14} \mathrm{CO}$ produced during the SPEs is also listed as fraction (in \%) of the annual global GCR produced background ${ }^{14} \mathrm{CO}$ (normalized to 1 molec $\mathrm{cm}^{-2} \mathrm{~s}^{-1}$ global average), both for normal cut-off rigidity $\left(f_{100 \%}\right)$, and for the reduced cut-off rigidity $\left(f_{20 \%}\right)$.

\begin{tabular}{|c|c|c|c|c|c|c|}
\hline Date & $\begin{array}{l}P_{0} \\
\mathrm{MV}\end{array}$ & $\begin{array}{l}I_{>30 \mathrm{MeV}} \\
\mathrm{cm}^{-2}\end{array}$ & $\begin{array}{l}Q_{100 \%} \\
\text { molec } \mathrm{cm}^{-2}\end{array}$ & $\begin{array}{l}f_{100 \%} \\
\% / \text { molec } \mathrm{cm}^{-2} \mathrm{~s}^{-1}\end{array}$ & $\begin{array}{l}Q_{20 \%} \\
\text { molec } \mathrm{cm}^{-2}\end{array}$ & $\begin{array}{l}f_{20 \%} \\
\% / \text { molec } \mathrm{cm}^{-2} \mathrm{~s}^{-1}\end{array}$ \\
\hline 12 Aug.-07 Sept. & 60.6 & $1.53 \cdot 10^{9}$ & $1.027 \cdot 10^{6}$ & 3.3 & $2.433 \cdot 10^{6}$ & 7.7 \\
\hline 29 Sept.-13 Oct. & 102.0 & $1.42 \cdot 10^{9}$ & $2.513 \cdot 10^{6}$ & 8.0 & $6.210 \cdot 10^{6}$ & 19.7 \\
\hline 19 Oct.-09 Nov. & 77.4 & $4.25 \cdot 10^{9}$ & $4.378 \cdot 10^{6}$ & 13.9 & $1.079 \cdot 10^{7}$ & 34.2 \\
\hline
\end{tabular}
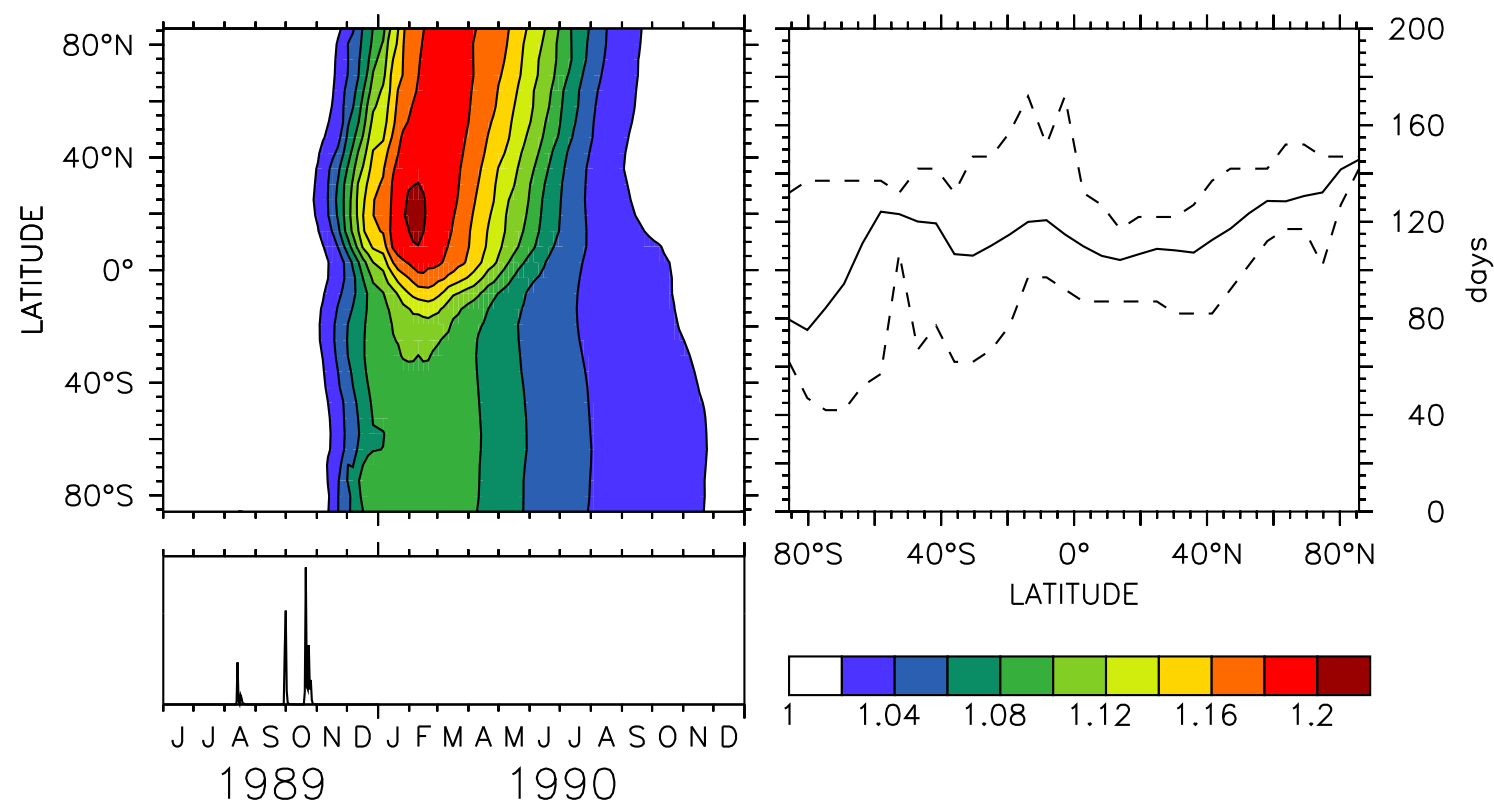

Fig. 3. Left: Zonally averaged enhancement of ${ }^{14} \mathrm{CO}$ (zonal mean ratio of the ${ }^{14} \mathrm{CO}$ mixing ratio calculated including $\mathrm{SPEs}$ to the ${ }^{14} \mathrm{CO}$ GCR background) in the lowest model layer after the 3 SPEs, calculated with the 3-D model for normal cut-off rigidity. The peaks in the lower panel are proportional to the ${ }^{14} \mathrm{CO}$ production of the respective SPEs. Right: Zonal average time lag between the largest SPE and the maximum excess ${ }^{14} \mathrm{CO}$ (solid line). The dashed lines indicate the maximum and the minimum predicted time lag at a given latitude.

\section{Observations of SPE produced atmospheric ${ }^{14} \mathrm{CO}$}

With the model predicting significant increases in ${ }^{14} \mathrm{CO}$, experimental verification is based on the Baring Head $\left(41.4^{\circ} \mathrm{S}\right.$, $174.9^{\circ} \mathrm{E}$, New Zealand) ${ }^{14} \mathrm{CO}$ record. This record (Fig. 4) commenced in June 1989 some months prior to the three strong SPEs, and comprises the only observational data available for this period.

The question whether ${ }^{14} \mathrm{CO}$ increases have been observed in the austral winter of $1989 / 90$ will be answered by comparing this period to that one exactly one year later as reference (no SPEs).

A potential complication is that a fraction of the atmospheric ${ }^{14} \mathrm{CO}$ inventory is not directly due to cosmic radiation, but originates from ${ }^{14} \mathrm{C}$ that has been recycled through the biosphere. All atmospheric $\mathrm{CO}$ produced from non-fossil organic compounds, by processes such as biomass burning or the oxidation of natural hydrocarbons in the atmosphere, contribute some ${ }^{14} \mathrm{CO}$. This fraction can be estimated. Background $\mathrm{CO}$ at southern mid-latitudes is 90 to $95 \%$ of biogenic origin, as fossil fuel sources are sparse and little CO is imported from the NH (Manning et al., 1997). However, even this small fraction from the $\mathrm{NH}$ contains a substantial fraction of biogenic $\mathrm{CO}$. Assuming that the background $\mathrm{CO}$ defined by the lower envelope (Fig. 4) (clear air, nonpolluted conditions at Baring Head) is $100 \%$ biogenic, then $1.52{ }^{14} \mathrm{CO}$ molecules $/ \mathrm{cm}^{3} \mathrm{STP}$, at the most, are estimated to be of biogenic origin in the $\mathrm{SH}$ (late) summer when the $\mathrm{CO}$ mixing ratio bottoms out at $\approx 40 \mathrm{nmol} / \mathrm{mol}$. This increases to $2.47 \mathrm{molecules} / \mathrm{cm}^{3}$ in spring (about $65 \mathrm{nmol} / \mathrm{mol} \mathrm{CO}$ ). Therefore, the fraction of biogenic ${ }^{14} \mathrm{CO}$ varies systematically between only $18 \%$ and $25 \%$. Because the baseline CO 


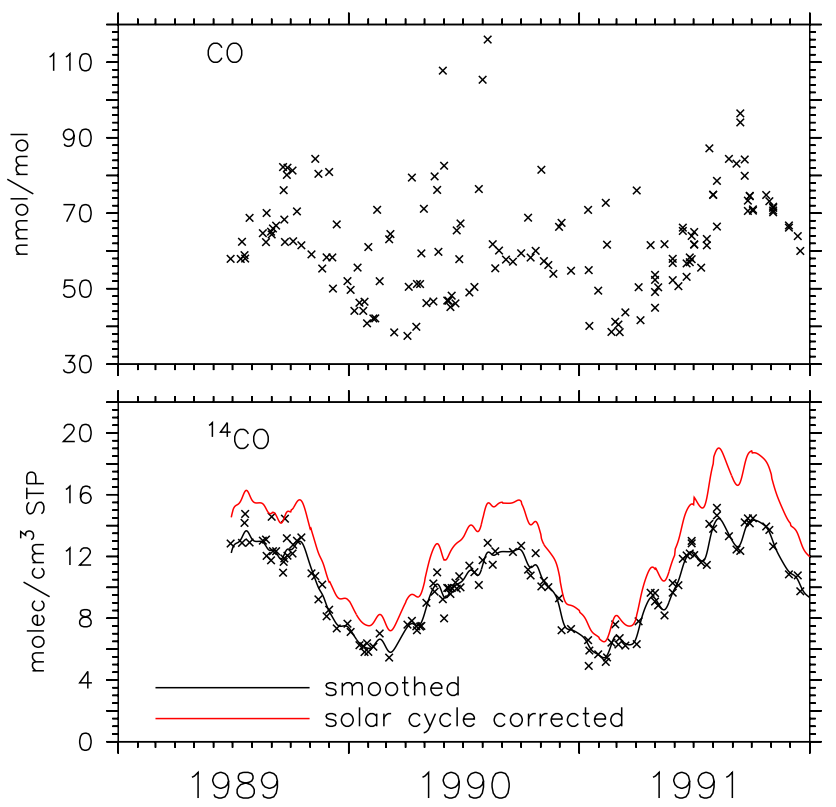

Fig. 4. $\mathrm{CO}$ (upper) and ${ }^{14} \mathrm{CO}$ (lower) measurements at Baring Head $\left(41.4^{\circ} \mathrm{S}, 174.9^{\circ} \mathrm{E}\right)$, New Zealand for the years 1989 to 1991 . The black solid line shows the result of the data smoothing, the red line indicates the smoothed data corrected with respect to solar variation of the GCR ${ }^{14} \mathrm{CO}$ background production rate using neutron count rates of the Mt. Wellington $\left(42.92^{\circ} \mathrm{S}, 147.25^{\circ} \mathrm{E}\right)$ neutron monitor. The scatter in $\mathrm{CO}$ is the result of $\mathrm{CO}$ from local sources during non background conditions. This $\mathrm{CO}$ is free of ${ }^{14} \mathrm{CO}$. Non clean air conditions were included to not bias the ${ }^{14} \mathrm{C}$ record towards specific meteorological conditions.

mixing ratios at Baring Head (Fig. 4) for the consecutive (late) summer periods did not differ by more than 5\%, biogenic $\mathrm{CO}$ cannot have affected observed ${ }^{14} \mathrm{CO}$ by more than about $1 \%$. Accordingly, no correction for biogenic ${ }^{14} \mathrm{CO}$ in comparing the two consecutive years is necessary.

The ${ }^{14} \mathrm{CO}$ time series (Fig. 4) is smoothed with a low-pass convolution filter of the form $f(t)=\exp \left((-t / T)^{2}\right)$ using a time window $T=1$ week in the frequency domain (by Fourier transformation) after linear interpolation to obtain daily values (linear interpolation to daily values does not introduce artificial oscillations, as long as no original data point is regarded to be an "outlier"). Because during 1989 and 1990 solar activity was at its maximum (solar cycle 22) it can be expected that the global average ${ }^{14} \mathrm{CO}$ background production did not vary significantly between the two years. To totally rule out effects related to changing solar activity, other than the SPEs, the ${ }^{14} \mathrm{CO}$ data further are normalized to equal conditions (Fig. 4) of solar activity using neutron monitor data of Mt. Wellington $\left(42.92^{\circ} \mathrm{S}, 147.25^{\circ} \mathrm{E}\right.$, Tasmania) assuming that the relative changes in amplitude of neutron count rate and of ${ }^{14} \mathrm{C}$ production during a solar cycle is the same. The resulting scaling of the global source strength is

$c_{q}(t)=\frac{n(t)}{n_{\mathrm{smin}}}$

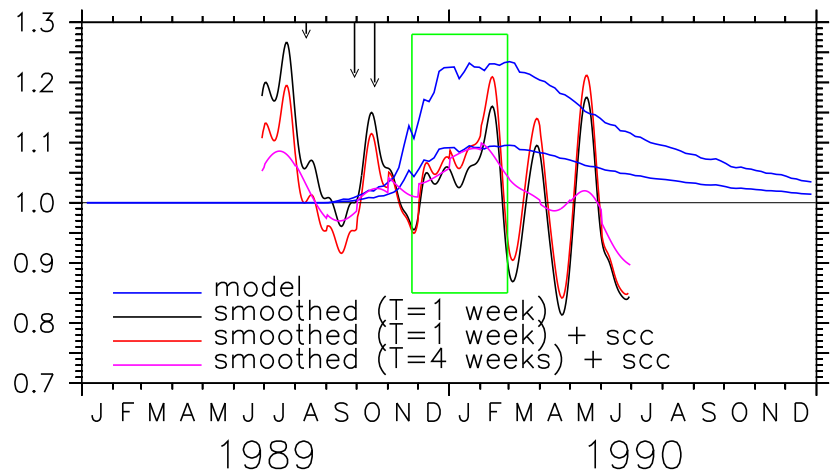

Fig. 5. Observed (black), and solar cycle corrected (scc) observed (red, cf. Fig. 4), enhancement of ${ }^{14}$ CO for June 1989 to June 1990 with June 1990 to June 1991 as reference year at Baring Head. The 3 SPEs in 1989 are indicated by the arrows at the top. The relative arrow-lengths correspond to the estimated total ${ }^{14} \mathrm{CO}$ production of the respective SPE. The blue lines show the results of the model prediction for normal cut-off rigidity (lower line) and an $80 \%$ reduced cut-off rigidity (upper line). The purple line shows the observations smoothed with a time window of $T=4$ weeks, and corrected for the solar cycle (scc).

where $n$ is the neutron count rate, $t$ is the time, and the index (smin) indicates solar minimum. Further, an average response time $\tau=3.5$ months for atmospheric ${ }^{14} \mathrm{CO}$ to changes in the global source strength is used for deducing the ${ }^{14} \mathrm{CO}$ mixing ratio time dependence (Jöckel et al., 2000). The ${ }^{14} \mathrm{CO}$ values are therefore scaled by

$c_{c}(t)=\sum_{i=1}^{12} w_{i} c_{q}(t-i)$

where $i$ counts the months backwards, $w_{0}=0.14$ is the estimated relative contribution of the current month's production rate, $w_{i} \propto \exp (-i / \tau)$, and $\sum_{i=0}^{12} w_{i}=1$. After having corrected the ${ }^{14} \mathrm{CO}$ record for modulation by solar activity, and having shown that the effect of changes in total $\mathrm{CO}$, via biogenic ${ }^{14} \mathrm{CO}$, are negligible, the remaining differences between the 2 consecutive years have only 2 possible causes. One is that synoptic scale changes in atmospheric circulation affect ${ }^{14} \mathrm{CO}$ levels. For instance, soon after the record had started in winter 1989, conditions of southerly air mass and southerly gales at the site were frequent in July and later again in October, leading to elevated ${ }^{14} \mathrm{CO}$ levels, manifest in Fig. 5 as the first 2 clear peaks.

However the three subsequent peaks (framed by the green box in Fig. 5) occur $117 \pm 2,89 \pm 2$ and $114 \pm 2$ days after the three SPEs, within the period for which the model predicts enhanced ${ }^{14} \mathrm{CO}$. The observed relative peak height does correspond to the strength of the SPEs in terms of the ${ }^{14} \mathrm{CO}$ production rate. Moreover, the time lag between each SPE and the respective measured maximum excess ${ }^{14} \mathrm{CO}$ does correspond to the characteristic rigidity of the events (Table 1). With increasing characteristic rigidity the SPE induced ${ }^{14} \mathrm{CO}$ 
production reaches deeper into the atmosphere and it takes less time to transport the excess signal to the surface. These are strong indications that these 3 peaks observed are indeed caused by the SPEs. Following these events, considerable oscillations in the ratio between the consecutive years occur related to strong changes in ${ }^{14} \mathrm{CO}$ in February-June 1991, again related to meteorological conditions. Moreover these peaks occur during the steep increase in ${ }^{14} \mathrm{CO}$ during fall. The rapid building up of a strong north south ${ }^{14} \mathrm{CO}$ latitudinal gradient augments the impact of synoptic scale meteorological differences.

For testing the sensitivity of resolving the 3 peaks to the sequence and distribution of actual data points, the analyses were repeated with reduced data sets from which randomly $10 \%$ of the data points had been omitted. All results obtained were very similar to the one using the complete set. This test provides, however, no measure for the statistical significance of the resulting signal, due to the limitations of the dataset. Only a few data points are causing the derived signal, and no data point is regarded to be an "outlier" in our analysis. More data are simply not available.

Finally, the influence of "meteorological noise" on the derived signal has been tested by smoothing the observed data with a longer time window of $T=4$ weeks. The result (including the correction for solar activity) is also shown in Fig. 5 (purple line). Due to their short time scale, the three individual peaks are not longer resolved. However, the observed signal becomes very similar to the model simulated signal for normal cut-off rigidity, whereas the oscillations outside the time interval in question (i.e., outside the green box in Fig. 5) are significantly reduced in amplitude. This is indeed an indication that the signals attributed to the SPEs are not caused by meteorological variations, in contrast to the other oscillations.

\section{Cross tropopause transport of SPE produced ${ }^{14} \mathrm{CO}$}

Because the timing of the transport of SPE ${ }^{14} \mathrm{CO}$ from the stratosphere into the troposphere is critical, an independent estimate is derived from the mean downward motion of air in the lower stratosphere at high latitudes using meteorological data. This downward motion can be regarded as a part of the global stratospheric Brewer-Dobson circulation (Holton et al., 1995). We diagnosed the Transformed Eulerian Mean (TEM) vertical velocity $\omega^{*}$ (Peixoto and Oort, 1992), using the 15 year (1979-1993) ECMWF reanalysis (ERA) data set (Gibson et al., 1997). The TEM circulation is the Eulerian mean circulation in which the part forced by eddy heat transport is removed. For each of the 180 months of the ERA period, the $\omega^{*}$ in the lower stratosphere has been diagnosed separately, with a latitudinal resolution of 2.5 degrees and at the levels of 10, 30, 50, 70, 100, 150, 250 and $300 \mathrm{hPa}$. The results applied in this study are 15-year August to November averages over the regions poleward of $60^{\circ}$, along with the
Table 2. ECMWF reanalysis based subsidence durations between the listed pressure levels in days for the northern hemisphere (NH) and the southern hemisphere (SH). The values are averaged over $60^{\circ}$ to $90^{\circ}$ latitude, and the months of August to November. For the averages of the years 1979 to 1993 the uncertainty is the standard deviation according to the year-to-year variation as described in the text. In addition, the respective subsidence times for the year 1989 are listed.

\begin{tabular}{lrrrr}
\hline Pressure $[\mathrm{hPa}]$ & \multicolumn{4}{c}{ subsidence duration [days] } \\
& SH & NH & \\
& $1979-1993$ & 1989 & $1979-1993$ & 1989 \\
\hline 30 to 70 & $129 \pm 39$ & 140 & $177 \pm 53$ & 222 \\
70 to 100 & $64 \pm 14$ & 60 & $75 \pm 21$ & 95 \\
100 to 150 & $40 \pm 6$ & 36 & $51 \pm 9$ & 58 \\
150 to 200 & $19 \pm 2$ & 17 & $23 \pm 3$ & 25 \\
200 to 250 & $15 \pm 2$ & 13 & $18 \pm 2$ & 19 \\
250 to 300 & $18 \pm 3$ & 17 & $16 \pm 2$ & 17 \\
\hline
\end{tabular}

respective averages for the year 1989. From $\omega^{*}$ the average subsidence time between the levels listed in Table 2 has been computed $\left(\Delta t=\Delta p / \omega^{*}\right)$.

The year-to-year variation of this subsidence time is computed (error propagation) as standard deviation $\sigma_{\Delta t}=$ $\left(\Delta p / \omega^{* 2}\right) \sigma_{\omega^{*}}$, where $\Delta p$ is the pressure interval, and $\sigma_{\omega^{*}}$ is the standard deviation of $\omega^{*}$ from the 15-year average. Computations for the two hemispheres of the extra-tropical average of $\omega^{*}$ (i.e. of the strength of the Brewer-Dobson circulation) using ERA data give generally somewhat larger (tens of $\%$ ) values than found in similar studies. For the $\omega^{*}$ as used in this study, averaged as described above, an educated guess of its accuracy is 50\%. More accurate vertical velocity data are presently not available. Assuming a time lag of 14 days for the air that just crossed the tropopause (Fig. 1) to reach the surface (tropospheric vertical mixing time), the maximum observed excess ${ }^{14} \mathrm{CO}$ at Baring Head induced by the three SPEs should then originate from a pressure level between $95 \mathrm{hPa}$ and $120 \mathrm{hPa}$, not considering the uncertainty in the subsidence velocity. With a 50\% overestimate of the subsidence velocity, the respective levels are $55 \mathrm{hPa}$ and $70 \mathrm{hPa}$. The maximum of the SPE induced ${ }^{14} \mathrm{CO}$ production rate is expected to be somewhat higher (see Fig. 1), at about $30 \mathrm{hPa}$, however depending further on the characteristic rigidity of the particular event and the cut-off rigidity. Furthermore, the production rate between $70 \mathrm{hPa}$ and $100 \mathrm{hPa}$ exhibits a significant contribution to the total SPE induced ${ }^{14} \mathrm{CO}$ production.

\section{Conclusions}

Based on GOES-7 satellite measurements of solar proton flux, we calculated the additional atmospheric ${ }^{14} \mathrm{CO}$ production caused by the 3 major SPEs in 1989. During the SPE periods of some days, the equivalent of $3.3 \%$ to $34.2 \%$ of 
the total annual GCR produced background ${ }^{14} \mathrm{CO}$ (normalized to 1 molec $\mathrm{cm}^{-2} \mathrm{~s}^{-1}$ global average production rate) has been produced in the stratosphere, whereby the individual fraction depends on the specific event and the cut-off rigidity. The downward transport of this SPE produced excess ${ }^{14} \mathrm{CO}$ was simulated with a 3D global chemistry transport model (CTM). For normal cut-off rigidity, the model predicts an increase of up to $22 \%$ in ${ }^{14} \mathrm{CO}$ at the surface (lowest model layer) with a location dependent time lag of 80 to 160 days after the SPEs. The corresponding peak increase at Baring Head, New Zealand, is calculated to be $9-10 \%$ between 2 and 5 months after the latest 1989 SPE.

Analysis of the ${ }^{14} \mathrm{CO}$ time series observed during 1989/1990 at Baring Head (which is the only existing ${ }^{14} \mathrm{CO}$ time series of that time) indeed revealed increased ${ }^{14} \mathrm{CO}$ levels following the 3 major 1989 SPEs, which in timing and intensity correspond to the flux and characteristic rigidity of the SPEs. The magnitude of the observed increase in ${ }^{14} \mathrm{CO}$ over the period of the 3 events is comparable to that calculated by the 3D model, using a normal cut-off rigidity. The reliability of the transport time estimates is further supported by independent meteorological analyses.

\section{Appendix: Model setup}

Model simulations have been performed with the 3dimensional global model of atmospheric transport and chemistry (MATCH) (Rasch et al., 1997) in the Max-PlanckInstitute for Chemistry (MPICH) version 2.0 (Lawrence et al., 1999). The employed SPITFIRE advection scheme (Rasch and Lawrence, 1998) is driven by re-analysed wind data from NCEP (Kalnay et al., 1996) using the year 1993 (inter-annual variations in transport and chemistry are neglected). The oxidative removal of ${ }^{14} \mathrm{CO}$ by $\mathrm{OH}$, its distribution in the troposphere (Lawrence, 1996) and the stratosphere (2-dimensional model calculations, Ch. Brühl, personal communication 2001) are described off-line (monthly averages). The small uptake of ${ }^{14} \mathrm{CO}$ by soils was also included (Conrad and Seiler, 1985; Sanhueza et al., 1998). The spatial distribution of GCR ${ }^{14} \mathrm{C}$ production (Lingenfelter, 1963) has been transformed from geomagnetic to geographic coordinates using altitude adjusted geomagnetic coordinates (AACGM) (Bhavnani and Hein, 1994). The distribution pattern is assumed to be constant, since the effect of the varying ${ }^{14} \mathrm{C}$ distribution with the solar cycle on atmospheric ${ }^{14} \mathrm{CO}$ is small (Jöckel et al., 1999). The varying global average source strength of GCR ${ }^{14} \mathrm{C}$ is parameterized by linear interpolation between solar maximum and minimum using monthly mean sunspot numbers (Lingenfelter, 1963). A yield of ${ }^{14} \mathrm{CO}$ from ${ }^{14} \mathrm{C}$ of $95 \%$ is assumed for both the GCR and the SPE component (MacKay et al., 1963; Pandow et al., 1960). The time dependence of the ${ }^{14} \mathrm{CO}$ production during the $3 \mathrm{SPEs}$ is derived from solar proton measurements on board the GOES-7 satellite. The total amount of ${ }^{14} \mathrm{CO}$ production is distributed (daily averages) according to the flux of protons with energy greater than $30 \mathrm{MeV}$ (Fig. 2). The model simulations were initialized with a global ${ }^{14} \mathrm{CO}$ distribution pre-calculated with the same model ( 2 year integration starting from zero mass mixing ratio) without SPEs. One model run including the 3 major SPEs (assuming normal cut-off rigidity) and one run without SPEs simulate the effect of the SPEs. Model output was archived as 5-day averages.

Acknowledgements. Support from the European Commission (DG $\mathrm{XII)}$ for the project ${ }^{14} \mathrm{CO}-\mathrm{OH}-E u r o p e$ is acknowledged, as is the EC SINDICATE project for supercomputer usage. We thank R. Thompson (IPS, Australia), J. E. Humble (Univ. of Tasmania), and J. Masarik for the shielding potential data. P. J. Crutzen, B. Steil, C. Brühl and R. C. Reedy contributed to discussions. R. Sparks (IGNS, New Zealand) carried out the ${ }^{14} \mathrm{CO}$ measurements. We especially acknowledge M. R. Manning and D. C. Lowe (both NIWA, New Zealand). The neutron data have been provided by the World Data Center WDC-C2 (Ibaraki, Japan), and the GOES-7 proton data by then National Geophysical Data Center - Space Physics Interactive Data Resource (NGDC-SPIDR, USA). We thank H. Sauer and and R. Zwickl (NOAA). The authors wish to acknowledge use of the Ferret program for analysis and graphics in this paper. Ferret is a product of NOAA's Pacific Marine Environmental Laboratory (information is available at www.ferret.noaa.gov). And last but not least, we thank two anonymous referees for their critical and constructive comments.

\section{References}

Bhavnani, K. H. and Hein, C. A.: An improved algorithm for computing altitude dependent corrected geomagnetic coordinates, Scientific Report No. 7, PL-TR-94-2310, Phillips Laboratory, Directorate of Geophysics, Air Force Material Command, Hanscom Air Force Base, Bedford, MA 01731-3010, 1994.

Brenninkmeijer, C. A. M.: Measurement of the abundance of ${ }^{14} \mathrm{CO}$ in the atmosphere and the ${ }^{13} \mathrm{C} /{ }^{12} \mathrm{C}$ and ${ }^{18} \mathrm{O} /{ }^{16} \mathrm{O}$ ratio of atmospheric CO with applications in New Zealand and Antarctica, J. Geophys. Res., 98, 10 595-10 614, 1993.

Brenninkmeijer, C. A. M., Manning, M. R., Lowe, D. C., Wallace, G., Sparks, R. J., and Volz-Thomas, A.: Interhemispheric asymmetry in $\mathrm{OH}$ abundance inferred from measurements of atmospheric ${ }^{14} \mathrm{CO}$, Nature, 356, 50-52, 1992.

Conrad, R. and Seiler, W.: Influence of temperature, moisture, and organic carbon on the flux of $\mathrm{H}_{2}$ and $\mathrm{CO}$ between soil and atmosphere: Field studies in subtropical regions, J. Geophys. Res., 90, 5699-5709, 1985.

Crutzen, P. J.: Solar proton events: Stratospheric sources of nitric oxide, Science, 189, 457-459, 1975.

Feynman, J., Spitale, G., Wang, J., and Gabriel, S.: Interplanetary proton fluence model: JPL 1991, J. Geophys. Res., 98, $13281-$ $13294,1993$.

Freier, P. S. and Webber, W. R.: Exponential rigidity spectrums for solar-flare cosmic rays, J. Geophys. Res., 68, 1605-1629, 1963.

Gibson, J. K., Kallberg, P., Uppala, S., Hernandez, A., Nomura, A., and Serrano, E.: ERA description, Tech. Rep. 1, ECMWF Re-Analysis Project Report Series, 1997. 
Holton, J. R., Haynes, P. H., McIntyre, M. E., Douglass, A. R., Rood, R. B., and Pfister, L.: Stratosphere-troposphere exchange, Rev. Geophys., 33, 403-439, 1995.

Jackman, C. H., Douglass, A. R., Rood, R. B., McPeters, R. D., and Maede, P. E.: Effect of solar proton events on the middle atmosphere during the past two solar cycles as computed using a two-dimensional model, J. Geophys. Res., 95, 7417-7428, 1990.

Jackman, C. H., McPeters, R. D., Labow, G. J., Flemming, E. L., Praderas, C. J., and Russell, J. M.: Northern hemisphere atmospheric effects due to the July 2000 solar proton event, Geophys. Res. Lett., 28, 2883-2886, 2001.

Jöckel, P. and Brenninkmeijer, C. A. M.: The seasonal cycle of cosmogenic ${ }^{14} \mathrm{CO}$ at the surface level: A solar cycle adjusted, zonal average climatology based on observations, J. Geophys. Res., 107, 4656, doi:10.1029/2001JD001 104, 2002.

Jöckel, P., Lawrence, M. G., and Brenninkmeijer, C. A. M.: Simulations of cosmogenic ${ }^{14} \mathrm{CO}$ using the three-dimensional atmospheric model MATCH: Effects of ${ }^{14} \mathrm{C}$ production distribution and the solar cycle, J. Geophys. Res., 104, 11 733-11 743, 1999.

Jöckel, P., Brenninkmeijer, C. A. M., and Lawrence, M. G.: The atmospheric response time of cosmogenic ${ }^{14} \mathrm{CO}$ to changes in solar activity, J. Geophys. Res., 105, 6737-6744, 2000.

Jöckel, P., Brenninkmeijer, C. A. M., Lawrence, M. G., Jeuken, A. B. M., and van Velthoven, P. F.: Evaluation of stratosphere - troposphere exchange and the hydroxyl radical distribution in 3-dimensional global atmospheric models using observations of cosmogenic ${ }^{14} \mathrm{CO}$, J. Geophys. Res., 107, 4446, doi:10.1029/2001JD001 324, 2002.

Kalnay, E., Kanamitsu, M., Kistler, R., Collins, W., Deaven, D., Gandin, L., Iredell, M., Saha, S., White, G., Woollen, J., Zhu, Y., Chelliah, M., Ebisuzaki, W., Higgins, W., Janowiak, J., Mo, K. C., Ropelewski, C., Wang, J., Leetmaa, A., Reynolds, R., Jenne, R., and Joseph, D.: The NCEP/NCAR 40-year reanalysis project, Bul. Am. Met. Soc., 77, 437-471, 1996.

Lawrence, M. G.: Photochemistry in the tropical troposphere: Studies with a global 3D chemistry-meteorology model, $\mathrm{PhD}$, Georgia Institute of Technology, 1996.

Lawrence, M. G., Crutzen, P. J., Rasch, P. J., Eaton, B. E., and Mahowald, N. M.: A model for studies of tropospheric photochemistry: Description, global distributions, and evaluation, J. Geophys. Res., 104, 26 245-26 278, 1999.

Libby, W. F.: Radiocarbon Dating, The University of Chicago, Chicago, 1952.
Lingenfelter, R. E.: Production of carbon 14 by cosmic-ray neutrons, Rev. Geophys., 1, 35-55, 1963.

Lingenfelter, R. E. and Ramaty, R.: Astrophysical and geophysical variations in $\mathrm{C} 14$ production, in Radiocarbon variations and absolute chronology, edited by I. Olsson, pp. 513-537, Wiley, New York, 1970.

MacKay, C., Pandow, M., and Wolfgang, R.: On the chemistry of natural radiocarbon, J. Geophys. Res., 68, 3929-3931, 1963.

Mak, J. E. and Southon, J. R.: Assessment of tropical OH seasonality using atmospheric ${ }^{14} \mathrm{CO}$ measurements from Barbados, Geophys. Res. Lett., 25, 2801-2804, 1998.

Manning, M. R., Brenninkmeijer, C. A. M., and Allan, W.: Atmospheric carbon monoxide budget of the southern hemisphere: Implications of ${ }^{13} \mathrm{C} /{ }^{12} \mathrm{C}$ measurements, J. Geophys. Res., 102, 10 673-10 682, 1997.

Pandow, M., MacKay, C., and Wolfgang, R.: The reaction of atomic carbon with oxygen: Significance for the natural radio-carbon cycle, J. Inorg. Nucl. Chem., 14, 153-158, 1960.

Peixoto, J. P. and Oort, A. H.: Physics of climate, Tech. rep., American Institute of Physics, 1992.

Rasch, P., Mahowald, N., and Eaton, B.: Representations of transport, convection, and the hydrologic cycle in chemical transport models: Implications for the modeling of short-lived and soluble species, J. Geophys. Res., 102, 28 127-28 138, 1997.

Rasch, P. J. and Lawrence, M. G.: Recent developments in transport methods at NCAR, in MPI-Hamburg Report No. 265, B. Machenhauer (Ed), 65-75, MPI-Hamburg, 1998.

Sanhueza, E., Dong, Y., Scharffe, D., Lobert, J. M., and Crutzen, P. J.: Carbon monoxide uptake by temperature forest soils: the effects of leaves and humus layers, Tellus, 50B, 51-58, 1998.

Sauer, H. H., Zwickl, R. D., and Ness, M. J.: Summary data for the solar energetic particle events of August through December 1989, Tech. rep., Space Environment Laboratory, NOAA, 1990.

Shea, M. A. and Smart, D. F.: Recent and historical solar proton events, Radiocarbon, 34, 255-262, 1992.

Stuiver, M. and Braziunas, T. F.: Sun, ocean, climate and atmospheric ${ }^{14} \mathrm{CO}_{2}$ : an evaluation of causal and spectral relationships, The Holocene, 3, 289-305, 1993.

Volz, A., Ehhalt, D. H., and Derwent, R. G.: Seasonal and latitudinal variation of ${ }^{14} \mathrm{CO}$ and the tropospheric concentration of $\mathrm{OH}$ radicals, J. Geophys. Res., 86, 5163-5171, 1981. 